\title{
DIALOGANDO SABERES - PESQUISA E PRÁTICA DE ENSINO NA FORMAÇÃO DE PROFESSORES DE CIÊNCIAS E BIOLOGIA.
}

Regina Mendes, Doutorado em Educação, Fac. Educação/UFMG (remendes@biologia.ufrj.br).

Danusa Munford, Faculdade de Educação /UFMG (danusa@ fae.ufmg.br).

É com prazer que apresentamos este número especial da Revista Ensaio, intitulado "Dialogando Saberes - pesquisa e prática de ensino na formação de professores de ciências". Nele, através de trabalhos exemplares do que tem sido produzido na Prática de Ensino do curso de Licenciatura em Ciências Biológicas da UFMG, pretendemos apresentar um panorama dessa produção e das suas implicações às discussões sobre a relação entre pesquisa e prática docente que têm despontado na literatura em ensino de ciências.

No momento em que amplas discussões sobre a Reforma Curricular têm se colocado nas IFES, consideramos que este se torna um espaço privilegiado para um debate sobre como a formação de nossos futuros professores têm sido encaminhada nos diferentes cursos de licenciatura dessas instituições. Organizamos este artigo introdutório em duas partes principais. Inicialmente, procuramos situar nossa experiência no contexto destas discussões acerca da formação inicial de professores, apontando o seu significado e contribuição para o debate. Na segunda parte do texto, apresentamos uma breve descrição dos trabalhos deste número especial.

\section{A Prática de Ensino em Ciências Biológicas: questões para discussão}

"Agora no final desta etapa do meu curso e após ter uma experiência (ainda que muito pequena) dentro de sala de aula, sou capaz de ver os enganos que cometi durante a minha própria formação como professor. Somente agora sou capaz de enxergar quão complexa é esta função que a princípio me parecia tão simples e relegada àqueles que não se adaptavam à pesquisa.

A função do professor é sobremaneira mais complexa que a função de pesquisador. Não basta ser aplicado ou simplesmente um gênio introspectivo. Tudo isto tem pouca valia nesta função tão abrangente. O professor deve acima de tudo saber lidar com 
pessoas e se adaptar a elas e às situações que podem ocorrer.

Além disso, esta regência serviu como base para um projeto de pesquisa em educação, algo que eu nem mesmo imaginava que fosse tão importante. Portanto, esta experiência ainda teve outra importância: o fato de abrir os nossos olhos para a atividade de pesquisa em educação pelo professor. Muito além do “cuspe e giz” estão estas atividades que se originam na prática, onde encontram seus problemas, para voltar à prática como uma forma de embasá-la e melhorá-la.

Assim encerro a minha etapa de formação dentro da faculdade, a minha fase de estudos, para iniciar a minha formação prática no ensino. Dentro desta prática, contudo, devo sempre buscar os elementos que poderão servir de base para novas pesquisas em educação, ou pelo menos estar consciente de que existe todo um aparato científico por trás da prática do professor, que tenta sempre ajudá-lo. E como um professor formado de forma consciente e dentro da fonte destas pesquisas, sei da minha responsabilidade em saber disto tudo e tentar buscar formas de me valorizar, valorizar a minha profissão e tentar sempre me manter em contato com este meio para que eu não me perca em meio à loucura que pode ser o cargo de professor. Neste país em que cada vez é mais difícil conseguir condições decentes para se dar aula, somente sendo professor para se entender a importância e as dificuldades enfrentadas pelos profissionais que formam e formarão as bases de tudo o que nos rodeia na sociedade.". (Filipe, aluno da prática de ensino).

O depoimento desse licenciando, ao final da disciplina Prática de Ensino de Ciências Biológicas na UFMG, reflete um dos principais desafios que as universidades enfrentam na formação inicial de professores: ajudar o futuro professor a entender a docência enquanto profissão e ter uma dimensão de sua complexidade e de suas especificidades. Esse desafio tem sido compartilhado por vários formadores, sendo que, nos cursos de licenciatura, as disciplinas de prática de ensino constituem-se como locus privilegiado para superá-lo, principalmente, por representarem um espaço no qual emergem tensões significativas.

Em recente trabalho (SELLES \& FERREIRA, 2003) ${ }^{1}$, Ferreira et al. procuraram "caracterizar as diferentes formas que a prática de ensino em Ciências Biológicas vêm assumindo na formação inicial de professores, visando compreendê-la nas relações que

\footnotetext{
${ }^{1}$ Lançado por ocasião da VI Escola de Verão para Professores de Prática de Ensino de Biologia, Física, Química e Áreas Afins (2003).
} 
estabelece com o espaço escolar." (FERREIRA et al., 2003:31). Para isso, selecionaram 35 de um total de 154 trabalhos publicados durante as últimas edições da Escola de Verão, "buscando compreender a prática de ensino em Ciências Biológicas quanto às suas formas de organização e suas finalidades" (FERREIRA et al., 2003:31).

Segundo as autoras, a análise dos trabalhos selecionados aponta que a organização da prática de ensino nos cursos de Ciências Biológicas está centrada não apenas nos objetivos e atividades escolares, mas também nas questões que a universidade propõe para o universo escolar. Complementando sua análise, as autoras apontam que as finalidades da prática de ensino nos cursos de Ciências Biológicas situam-se em 2 dimensões de natureza distintas: "na primeira, podemos reunir as atividades que buscam criar oportunidades de vivências pedagógicas; na segunda, situamos aquelas que priorizam a pesquisa como componente formativo da prática de ensino."(FERREIRA et al., 2003:34).

As oportunidades de vivências pedagógicas são apresentadas na forma de elaboração de materiais didáticos, de atividades que êm por base questões que a própria universidade julga relevantes para o ensino de ciências e biologia, ou de vivências nas quais os licenciandos atuam fortemente no fazer docente. Já no caso dos trabalhos onde a pesquisa é o foco de formação, as autoras apontam 3 finalidades distintas: levantamento de dados e/ou da proposição de soluções para o enfrentamento dos problemas educacionais; atividade de pesquisa como meio de transformação das concepções de ciência e de ensino-aprendizagem; e formação de profissionais que, além de professores, tornem-se também pesquisadores.

A partir da análise apresentada, podemos perceber diferentes objetivos e propostas de atividades permeando o campo da formação inicial de professores de ciências. Porém, o mais interessante é notar uma forte tendência à vinculação desses objetivos e atividades às questões que fundamentam a prática de ensino e a prática docente, e não mais às questões teórico-metodológicas centradas na transmissão do conteúdo específico:

"Assim, podemos afirmar que os textos analisados convergem ao compreender a formação inicial como um empreendimento educativo que supera o modelo centrado na transmissão dos conteúdos científicos. Do mesmo modo, visam a oferecer alternativas para superar os modelos de formação baseados na racionalidade técnica. Desta forma, refletem um esforço de incorporar as críticas que, historicamente, foram elaboradas nas universidades quanto à reprodução de tais modelos, segundo as quais aprender a ser 
professor não se reduz a ter domínio dos conteúdos e/ou a aplicar técnicas de ensino." (FERREIRA et al., 2003:37).

Não é surpreendente que estas novas abordagens inspiradas no questionamento da visão tecnicista de formação de professores pareçam predominar dentro de disciplinas integradoras da licenciatura, que êm como objetivo estabelecer relações entre teoria e prática - como a Prática de Ensino. O trabalho dos educadores responsáveis por estas disciplinas inevitavelmente envolve entender as tensões e idiossincrasias da atuação do professor nesta interface entre ciência e educação. Contudo, diante das discussões acerca das reformas na formação inicial dos professores, é fundamental examinar os cursos de licenciatura em ciências como um todo, abrangendo disciplinas que abordam conteúdos específicos da disciplina que o professor irá lecionar (freqüentemente de responsabilidade do instituto de origem do aluno) e disciplinas pedagógicas (em geral, de responsabilidade da faculdade de educação) ${ }^{2}$. Tal olhar revela uma realidade muito mais complexa, a qual afeta todos os educadores envolvidos no curso. Uma das questões em pauta atualmente é a natureza fragmentada dos cursos de licenciatura em ciências, que seguem o chamado modelo [3+1], retrato da limitada interlocução entre profissionais envolvidos na formação de professores (CARVALHO, 2001). Em suma, as experiências no contexto da disciplina Prática de Ensino teriam um significado mais abrangente se consideradas dentro deste contexto amplo e não de forma isolada.

No caso particular da Licenciatura em Ciências Biológicas da UFMG, pesquisas indicam, por exemplo, que lá uma grande diversidade de representações do trabalho do professor do ensino básico entre os formadores ${ }^{3}$, sendo a noção de professor enquanto transmissor bastante freqüente (PEREIRA, 2000).

\section{Saberes Docentes e Formação Inicial de Professores}

Além da visão do professor como mero aplicador-transmissor dos conhecimentos produzidos pelos acadêmicos, um outro tipo de reducionismo vem prejudicando a imagem da profissão docente: o que diz que para ser professor "basta ter o dom".

\footnotetext{
${ }^{2}$ Inclusive, as disciplinas no instituto de origem compõem a maior parte da carga horária dos cursos de licenciatura (CARVALHO, 2001).

${ }^{3}$ Neste caso, consideramos formadores de professores todos os professores universitários do curso de licenciatura - tanto do instituto de origem (i.e., o Instituto de Ciências Biológicas) quanto da Faculdade de Educação.
} 
A ênfase exagerada no "dom" desvaloriza o empenho e o investimento que os professores fazem na sua formação inicial e continuada. Ao enfatizar um aspecto "divino", "mágico" ou "esotérico" da habilidade de ensinar, essa visão desconsidera a necessidade de esforço, trabalho e reflexão na prática do professor, tornando-a então uma prática menor se comparada a outras atividades profissionais. A busca contínua por novos conhecimentos e pela atualização dos conhecimentos já adqüiridos, o desenvolvimento e a descoberta de novos materiais e metodologias pedagógicas e a reflexão constante, através de leituras, pesquisas e troca de experiências sobre sua atividade e as inovações na área descartam essa visão "profética" do professor e mostram que esse ofício possui conhecimentos, habilidades, competências e saberes específicos e necessários ao bom desempenho de seus profissionais. Ser professor, portanto, é mais do que saber o conteúdo ou ter um dom. Segundo TARDIF et al. (1991:228), o exercício cotidiano da profissão docente exige "uma cota de improvisação e de habilidade pessoal, bem como a capacidade de enfrentar situações mais ou menos transitórias e variáveis". Além disso, os autores frisam que

"A atividade docente não se exerce sobre um objeto, sobre um fenômeno a ser conhecido, ou uma obra a ser produzida. Ela se desdobra concretamente numa rede de interações com outras pessoas, num contexto onde o elemento humano é determinante e dominante, e onde intervêm símbolos, valores, sentimentos, atitudes, que constituem matéria de interpretação e decisão, indexadas, na maior parte do tempo, a uma certa urgência." (TARDIF et al., 1991:228).

Diante dessas situações e a partir do contexto descrito, o professor deve julgar e fazer escolhas difíceis, que são auxiliadas pelos saberes que ele possui (GAUTHIER et al., 1998) e que são construídos ao longo do exercício da sua profissão.

Um exame mais atento da história do curso de Licenciatura em Ciências Biológicas na UFMG novamente traz à tona tensões em relação aos cursos de formação de professores de ciências que acabam por banalizar a profissão docente. Em sua origem, os objetivos da formação de biólogos naquela instituição não foram explicitados, mas a percepção daqueles que concluem o curso parece indicar contradições que ainda permeiam o contexto atual. A princípio, o objetivo de formar pesquisadores em Ciências Biológicas seria mais valorizado, contudo, tal objetivo não necessariamente norteava as práticas docentes. Além disso, as oportunidades para o biólogo atuar profissionalmente eram (e são) consideravelmente limitadas, sendo que havia (e há) uma grande demanda por 
professores do ensino básico na área de ciências e biologia. Assim, apesar de sua futura atuação provavelmente ser como professor, o aluno de graduação era formado tendo em mente o ideal de formação de pesquisadores em ciências naturais. Tal ênfase na pesquisa em Ciências Biológicas reflete-se, por exemplo, na definição do currículo dos cursos a partir de demandas e preocupações relacionadas ao bacharelado (PEREIRA, 2000). Portanto, no percurso de sua formação enquanto biólogo, o aluno, de fato, não tem uma vivência da docência como profissão que demanda saberes específicos. Em outras palavras, os saberes envolvidos na formação de "biólogos pesquisadores" são colocados como suficientes para a formação do "biólogo professor".

$\mathrm{Na}$ área de Educação, a valorização de outra faceta do professor — de um profissional que possui saberes específicos que auxiliam no exercício de sua profissão — surge quando a atividade docente passa a ser considerada como um fator influente nos processos de ensino-aprendizagem (GAUTHIER et al., 1998:60). Como desdobramento, o debate sobre a importância dos saberes docentes na formação inicial dos professores aparece a partir da utilização da pesquisa como ferramenta para o ensino (FERREIRA et al, 2003:39; LUDKE, 2001:81). Assim, podemos argumentar que na prática de ensino a pesquisa surge muitas vezes como um "princípio educativo e formativo". (ANDRÉ, 2002; 1994; DEMO, 1996; 1994; 1991).

\section{Pesquisa e Prática de Ensino: dialogando saberes}

A prática de ensino como um espaço de pesquisa busca romper com a dissociação entre teoria e prática recorrentemente encontrada nos currículos de formação inicial e que se traduz na divisão entre disciplinas conteudistas, técnicas ou instrumentais (responsabilidade dos cursos de origem) e disciplinas pedagógicas ou de caráter eminentemente prático (responsabilidade das faculdades de educação). Na prática de ensino, busca-se a integração entre a prática e os conhecimentos teóricos, através de sua aplicação, reflexão, debate e reelaboração. Além disso, muitas vezes é na prática de ensino que o licenciando terá o primeiro contato real e contínuo com a escola como espaço de produção e apropriação de conhecimentos; com a visão do trabalho do professor através dos seus saberes experienciais, práticos; com os dilemas dessa profissão e os desafios que hoje se colocam na vivência da prática docente. 
Podemos levantar, a partir dessa visão, algumas contribuições da relação que pode ser produzida entre a prática de ensino e a pesquisa em educação. A primeira é a constatação da prática de ensino como "objeto de estudo privilegiado, uma vez que, historicamente, tem ocupado um tempo significativo na formação profissional destes estudantes.'(FERREIRA et al, 2003:36). Outra contribuição importante é mencionada por Ludke, quando aponta que, de maneira singular, os especialistas das chamadas áreas científicas "ressaltam o papel da pesquisa como fator formador da própria concepção da matéria e da maneira de ensiná-la, como um saber em construção." (LUDKE, 2002:118). Uma terceira contribuição da relação entre pesquisa e prática de ensino configura-se principalmente no campo do conhecimento escolar e dos saberes docentes, ao demonstrar a sua importância na formação do professor, relativizando e desmistificando o domínio historicamente instaurado do trabalho do pesquisador, do cientista, sobre o trabalho do professor (FERREIRA et al, 2003; MENDES, 2002; GAUTHIER, 1998; TARDIF, 1991).

É importante tecermos algumas considerações sobre a diferença entre a pesquisa sobre o conhecimento científico e a pesquisa sobre o conhecimento escolar (incluindo o contexto escolar e/ou a prática e os saberes docentes). Durante muito tempo, esta não foi considerada como "pesquisa", sendo somente valorizada pela academia a pesquisa sobre o conteúdo científico - sua produção e aplicação. Esta "tradição" fez com que a valorização das pesquisas sobre o professor e a escola permanecessem ligadas às proposições de pesquisa realizadas por acadêmicos e não pelos sujeitos da ação, que são os professores da escola básica. Sendo assim, os problemas analisados e "solucionados" pela academia partem muitas vezes de perguntas elaboradas por pesquisadores, e não por professores. Como consequência, as respostas são consideradas boas para a academia, mas não para a escola real, repleta de contradições e de complexidade (LUDKE, 2001). Com isso, cria-se uma cultura do menosprezo: de um lado, pesquisadores que menosprezam os problemas reais apontados pelos professores; do outro lado, professores que menosprezam as soluções dadas pelos pesquisadores.

Sobre esta questão, Ludke nos mostra outras nuances do processo, ao refletir que...

"Essa dualidade de perspectivas revela, ao mesmo tempo, w professor a percepção de que a pesquisa acadêmica não consegue atingir os problemas e os temas mais importantes e próximos do seu trabalho na escola, mas que ela provavelmente domina os métodos e os recursos necessários para investigar devidamente aqueles assuntos 
fundamentais. A pesquisa que ele faz, ou poderia fazer em sua escola, parece não ter, aos seus olhos, a capacidade de dominar plenamente o conhecimento do objeto desejado, mas não há dúvidas de que ele é quem sabe qual é esse objeto (não o pesquisador da academia). Seu saber parece ficar pairando em um interstício, situado entre o que ele domina pela sua aprendizagem anterior em confronto com o que sua experiência vem confirmando e sua aspiração de expansão desse saber, por meio de recursos que poderão vir da pesquisa, talvez, não necessariamente. Em todo caso, seu trabalho presente não depende dela, aparentemente. Não da pesquisa tradicional, canônica, embora ela continue a funcionar como modelo distante, aprendido na instituição formadora e atuante até hoje." (LUDKE, 2001:89).

Portanto, é necessário que reafirmemos a importância das pesquisas que partem do próprio ambiente escolar e que retornam a ele na forma de propostas, reflexões e possíveis soluções. Com relação aos trabalhos da prática de ensino, Ferreira et al concluem seu artigo mostrando que os saberes acadêmicos ainda são a principal referência sobre a qual a formação docente têm se contruído no Brasil. E alertam, portanto, para a necessidade de uma maior interação com a escola e de uma interlocução com os saberes elaborados por professores ao longo de suas experiências profissionais (FERREIRA et al., 2003:42). As Diretrizes Curriculares para a Formação Inicial dos Professores para a Educação Básica trazem, por exemplo, a proposta de obrigatoriedade de 400 horas de estágio, visando justamente dar maior ênfase para estes saberes. Paralelamente, uma das resoluções do CNE aponta como um dos aspectos para a definição de princípios norteadores de cursos de formação de professores "a pesquisa com foco no processo de ensino e de aprendizagem, uma vez que ensinar, requer, tanto dispor de conhecimentos e mobilizá-los para a ação, como compreender o processo de construção do conhecimento",4. Esses elementos indicam uma valorização da integração do conhecimento construído na academia e das experiências vivenciadas na escola, bem como incorporam uma nova visão acerca do trabalho docente. Porém, devemos ser cautelosos pois em primeiro lugar, a simples inclusão na grade horária de tempo significativo de estágio nas escolas do ensino básico, bem como a implementação de trabalhos de conclusão de cursos não é suficiente para promover tal integração. É fundamental que continuemos a reconhecer o papel do conhecimento acadêmico e da universidade na formação de professores, tanto quanto a importância das experiências práticas proporcionadas pelo estágio escolar.

\section{A Formação Inicial e a Oportunidade de Encontro e Geração de Saberes Docentes:}

\footnotetext{
${ }^{4}$ Artigo $3^{\circ}$ parágrafo III da ResoluçãoCNE/CP1/2002
} 


\section{uma experiência na prática de ensino do curso de Licenciatura em Ciências Biológicas da UFMG}

Em sua ementa, a disciplina Prática de Ensino em Ciências Biológicas para o período diurno propõe-se a promover uma reflexão acerca dos objetivos do ensino de ciências e biologia, bem como fornecer subsídios para seu planejamento. A expectativa é que isto ocorra no contexto de experiências docentes em escolas da comunidade. Nos últimos anos, os professores responsáveis pela disciplina têm incluído dentre as tarefas a serem cumpridas um trabalho de pesquisa na área de ensino de ciências e biologia. Portanto, tradicionalmente, esta disciplina busca alcançar objetivos bastante amplos, envolvendo atividades diversas, que vão desde aulas teóricas até a elaboração de pesquisas completas, passando pelo estágio escolar e por atividades de regência em sala de aula. Naturalmente, contemplar esta gama de objetivos e atividades tem representado um grande desafio para os formadores, afinal, a disciplina é composta por 8 créditos cumpridos no último semestre do curso de licenciatura. No primeiro semestre de 2004, a primeira autora foi a principal responsável pela disciplina, organizando a prática de ensino em Ciências Biológicas em torno dos seguintes objetivos, baseados no respeito ao professor e numa formação inicial sólida:

1. conhecimento sobre a literatura em educação em ciências;

2. contato com as pesquisas em ensino de ciências;

3. conhecimento in situ do espaço escolar e do trabalho docente;

4. envolvimento com as atividades de sala de aula;

5. reflexão sobre o ensino de ciências;

6. reflexão sobre a atividade docente;

7. contato com a linguagem e os saberes dos professores;

8. reflexão coletiva e debates sobre os dilemas e dificuldades da prática docente;

9. proposição e/ou investigação de temas de pesquisa sobre educação em ciências.

A partir desses objetivos, foi elaborado um currículo semestral de atividades, que contemplaram aulas teóricas (itens 1 e 2); estágio escolar (itens 3 a 7); atividades de regência (item 4); confecção de: autobiografia (itens 5 e 6), relatório de observação ( itens 3, 4, 6 e 7) e relatório de estágio (itens 4 a 7); atendimentos em grupo (item 8) e preparação de projetos de pesquisa (itens 1, 2 e 9). 
Entendemos com isso que são 3 os fundamentos da formação de futuros professores de ciências:

1. A atuação do professor é mediada pelo espaço escolar e pelo conhecimento produzido inerentemente nessa instância de ensino - a escola;

2. O exercício da docência passa pela apreensão e produção de saberes necessários e exclusivos a esta profissão, e ser professor envolve uma imersão no seu cotidiano, nos seus hábitos, na sua forma de expressão e nos dilemas e dificuldades que atravessam sua prática; e

3. A pesquisa em educação e em ensino de ciências vêm contribuir para a formação do futuro professor a partir do momento que ajuda-o a entender a prática docente e as teorias que procuram fundamentar essa prática.

Coerentemente à nossa proposta e aos seus fundamentos, encontramos entre os alunos depoimentos que destacam a importância, para a sua formação como professores, da aproximação que obtiveram com a pesquisa em educação, com o cotidiano escolar, com as formas de atuação do professor regente durante a prática docente, assim como sobre a compreensão da complexidade da relação professor-aluno. Como exemplo do resultado desse trabalho, apresentamos o seguinte depoimento:

"Durante grande parte do curso de licenciatura, entramos em contato com diversas faces do fazer pedagógico. Temos aulas de sociologia, psicologia, didática, política, métodos de ensino de botânica, zoologia e ecologia. Estudamos teorias, técnicas e métodos, refletimos e discutimos sobre o professor, o aluno, a sala de aula e a escola. Tudo isto nada representa, até colocarmos os pés em uma sala de aula.

O primeiro dia de estágio a gente nunca esquece. Os olhares inquietos dos alunos frente à novidade do novo professor, aquele frio na barriga que não cessa. O que devo fazer? O que devo falar? Andando de um lado para outro da sala, com as mãos nos bolsos ou cruzadas, na vã esperança inconsciente de esconder o nervosismo. Milhares de dúvidas dentro da cabeça, devo ser o professor amigo, carrasco, ou meio termo? Como alcançar o equilíbrio? Perguntas básicas, perguntas complexas, mas que vão sendo respondidas ao longo do caminho. Basta para isso a sensibilidade, a atenção e a humildade, para reconhecer, em uma pergunta, uma atitude ou até mesmo um olhar de aluno, a resposta. Respostas que são construídas no dia-a-dia de uma sala, respostas 
que nascem da prática, bem feita, consciente. Não há nada sem a prática. Não há teoria, não há método, não há reflexão. Dela vem as dificuldades, a matéria prima das discussões. Dela vem até mesmo, as respostas. (...)”. (Thiago, aluno da prática de ensino)

A reflexão desse aluno mostra que a integração entre os métodos e as teorias que guiam o currículo da disciplina Prática de Ensino são essenciais para se desnaturalizar a dicotomia existente entre teoria e prática pedagógica, que persiste na formação do aluno desde a estrutura curricular de seu curso de Ciências Biológicas, até muitas vezes a forma como se dá a prática de ensino - com aulas teóricas e discussão de textos no começo, e o cumprimento muitas vezes burocrático do estágio curricular no final do curso. Uma outro fator que nos chama atenção no depoimento de Thiago, é a importância da abertura de um diálogo dentro da prática de ensino, entre professor e licenciandos, para o enfrentamento dos conflitos e dificuldades que surgem durante o estágio curricular.

Nesse sentido, gostaríamos de destacar que algumas estratégias adotadas ao longo do semestre tiveram papel fundamental no sentido de promover esse apoio. Foi o caso dos atendimentos em grupo. Apesar de normalmente as turmas de prática de ensino serem compostas por no máximo 20 alunos, a especificidade e importância desse curso para a formação dos futuros professores permite que a atenção do professor seja muito mais direcionada a cada licenciando do que em outras disciplinas do currículo da licenciatura. Atenta a isso, a primeira autora realizou nesse mesmo semestre letivo uma experiência com a turma de prática de ensino em Ciências Biológicas do curso diurno: para os trabalhos coletivos e os atendimentos sobre o estágio, a turma dividiu-se em grupos de 3 a 5 alunos. Durante os horários de atendimento, esses grupos encontravam-se com a professora de prática de ensino e tinham a oportunidade de falar sobre o andamento de seus estágios individuais, assim como pôr em discussão outros assuntos da prática que eram do interesse de todo o grupo. A professora de prática fazia o mesmo, e deste modo pôde ter a oportunidade de discutir com mais qualidade o andamento dos estágios, entre outras dúvidas e dificuldades dos alunos. O resultado dessa experiência pode ser percebido na reflexão de uma das alunas participantes, reflexão essa transcrita do seu relatório de estágio:

\footnotetext{
${ }^{5}$ Dos 10 relatórios produzidos, 8 estavam disponíveis no momento do levantamento.
} 
"Realmente não existe uma receita para a aula ou para o plano de aula perfeito. Existe sim a ajuda de professores e colegas para que o nosso desempenho em sala de aula seja o melhor possível. Acredito que os momentos mais valiosos deste estágio foram os atendimentos em grupo, onde os fatos vivenciados na escola viravam reflexões importantes para compreender essa nova realidade que nos foi mostrada. O mais interessante era que, muitas vezes, a vivência de um se tornava um ponto a ser pensado por todos, a fim de se encontrar numa melhor postura para se enfrentar a situação.”. (Lia, aluna da prática de ensino).

É importante perceber na reflexão de Lia como a forma de lidar com os problemas de sala de aula adquire uma perspectiva muito mais complexa, sem que se ponha a culpa dos problemas da prática no professor da turma, nos alunos, na estrutura escolar ou no desempenho do próprio licenciando. Eles passam a perceber que estes problemas não têm solução fácil, e que a sua formação como professor não estará pronta ao final do curso. Com os estágios e as discussões no decorrer da disciplina, os licenciandos entendem que a formação do professor é permanente, e que o "segredo" para uma "boa aula" está na prática, na vivência da profissão, na percepção que esta é singular, complexa, repleta de decisões difíceis; decisões estas que na maior parte das vezes devem ser tomadas em situações de urgência e incerteza.

A importância deste diálogo com pares e formadores, trazida pelos atendimentos em grupo, não é surpreendente se partimos da perspectiva de que a aprendizagem deve ser entendida como participação em uma comunidade (LAVE \& WENGER, 1991), a partir do domínio das práticas e discursos de seus componentes (DRIVER et al., 1999; BROWN et al., 1989). Alguns autores inclusive argumentam que na formação de professores é essencial que invista-se na constituição de comunidades de professores (PUTMAN \& BORKO, 1997). Além disso, consideramos que a parceria com a área acadêmica, visando a elaboração e produção de projetos de pesquisa junto com os professores e que tenham o espaço escolar como objeto de estudo, é bem-vinda. Exemplos de que isso já acontece são os trabalhos de colaboração e de desenvolvimento profissional de professores que têm se firmado nos últimos tempos (MENEZES, 2003; MIZUKAMI, 2002; FIEN \& RAWLING, 1996). Esta parceria também parece ser o espaço de direito das pesquisas sobre e na prática de ensino, pois sem dúvida ela se constitui legitimamente na relação entre a universidade (na figura dos cursos de formação inicial, e muitas vezes continuada) e a escola. 
Partindo dos depoimentos aqui retratados, acreditamos que esse movimento dos licenciandos no sentido de reconsiderar suas perspectivas - de biólogos que não valorizam o trabalho do professor, para futuros professores que entendem a singularidade e as especificidades da sua profissão - também se deve a um contato com a literatura sobre conhecimento escolar e saberes docentes, assim como com a pesquisa em ensino de ciências. Este contato, proporcionado pelas aulas teóricas de prática de ensino, assim como pela proposição de temas de pesquisa sobre educação em ciências pelos próprios licenciandos, despertou-os também para as possibilidades de investigação dos problemas e especificidades do contexto da sala de aula de ciências. Essas questões começaram a surgir durante os estágios, e resultaram nos trabalhos que compôem esse número especial da Revista Ensaio.

A importância desse tipo de pesquisa para a formação de professores, seus limites e possibilidades são assim apresentados por Shulman:

“(...) Não se espera da pesquisa, na qual se apóia a prática profissional, que confira conhecimento certo, mas antes que ofereça guias para a prática. Ela oferece maneiras de reduzir a incerteza, mas não de removê-la. Ela oferece precedentes e exemplos, mais do que regras claras. Ela informa o julgamento, mas raramente alivia o profissional de suas atribulações. Ela contribui com padrões (standards) de prática, mais do que regras de procedimento. Ao deslocar-se do conhecimento disciplinar para o terreno da prática profissional, muda-se de um domínio puramente intelectual para um no qual princípios teóricos, práticos e morais se conectam, colidem e convergem infinitamente.". (SHULMAN, 1999:163 apud LUDKE, 2001:86).

\section{Considerações Finais}

Ao longo deste texto, procuramos mostrar como a pesquisa e a prática docente têm dialogado na formação dos professores de ciências e biologia, através dos objetivos e pressupostos da disciplina Prática de Ensino em Ciências Biológicas da UFMG. A partir de uma análise realizada recentemente das formas de organização e das finalidades de cursos afins (FERREIRA et al, 2003), iniciamos uma exposição sobre como a pesquisa e a prática docente, assim como o contexto escolar, têm permeado as atividades de nosso curso. Mostramos como as vivências pedagógicas e as atividades de pesquisa têm sido nele contempladas de forma complementar, assim como fundamentamos nossa 
opção por enfatizar uma formação teórica e prática dos saberes dos futuros professores a partir da rejeição de um modelo de professor como aplicador de conhecimentos. Para nós, os professores são produtores de conhecimentos que encontram no espaço escolar o lugar de direito para a vivência, discussão, reflexão e aplicação dos seus saberes, sejam estes disciplinares, pedagógicos, experienciais ou de outra natureza.

Aliada e indissociável dessa formação, consideramos a pesquisa um princípio educativo e formativo quando ajuda o futuro professor a entender a prática docente e as teorias que procuram fundamentar essa prática. Dessa forma, incentivamos a iniciação dos licenciandos nas pesquisas em Educação que buscam as especificidades e os dilemas do contexto escolar e da atuação do professor. Os trabalhos a serem apresentados aqui são portanto o reflexo dessa prática.

\section{Sobre os Artigos Presentes neste Número Especial}

Os artigos que compõem esse número especial da Revista Ensaio foram selecionados no intuito de demonstrar a diversidade na produção de trabalhos de iniciação à pesquisa em ensino pelos licenciandos em Ciências Biológicas da UFMG. Essa diversidade pode ser entendida a partir de dois eixos: o eixo da diversidade de olhares sobre o objeto de pesquisa e o eixo da diversidade de foco de pesquisa. Assim, consideramos tanto quem pesquisa e de que lugar esse pesquisador fala, assim como sobre o quê se pesquisa e suas implicações na própria formação do professor-pesquisador.

No artigo "A Percepção de Alunos do PROEF II sobre a Importância das Aulas Práticas: uma abordagem investigativa", Adriana Cristina Souza Leite, Pollyana Alves Borges e Ana Cristina Ribeiro Vaz abordam o ensino de ciências na educação de jovens e adultos a partir da experiência da primeira autora como monitora-professora desse segmento educativo, e também licencianda em Ciências Biológicas na UFMG. A investigação da importância das aulas práticas para esses alunos lança também um olhar sobre as estratégicas didáticas da própria monitora-professora/licencianda, assim como sobre as escolhas pedagógicas do grupo que compõe o projeto abordado.

\footnotetext{
${ }^{6}$ Existem temas que aparecem mais de uma vez em cada um dos 8 relatórios analisados, assim como alguns temas não aparecem obrigatoriamente em todos os relatórios analisados.
} 
Fernanda Reis de Pinho Tavares, em seu artigo "Educação Ambiental na Escola: a perspectiva estudantil sobre o meio ambiente e a propaganda ambiental na Internet", investiga a evolução das idéias de estudantes sobre a propaganda, refletindo como ela se insere na questão ambiental. A autora, licencianda em Ciências Biológicas na UFMG, escolhe esse tema a partir de seu próprio trabalho com turmas do ensino fundamental em oficinas pertencentes à grade curricular da escola onde leciona, mas que são de escolha optativa pelos alunos. Assim, lança um olhar sobre os processos de inovação escolar que baseiam as suas escolhas como professora em formação, e que envolvem o currículo (oficinas), o conteúdo (educação ambiental, propaganda) e as estratégias pedagógicas (Internet).

Já Ana Luiza Paiva e Carmen De Caro, em seu artigo 'Concepções prévias de Alunos de Terceiro Ano do Ensino Médio a Respeito de Temas na Área de Genética", investigam as concepções dos alunos sobre temas na área de genética a partir de levantamento feito durante o estágio curricular da primeira autora, no qual a segunda autora foi sua professora regente. Desta forma, é interessante ver essa pesquisa sobre o olhar de uma parceria que envolve a formação do licenciando e sua inserção no universo de trabalho do professor, e o enriquecimento que essa troca pode proporcionar para ambos.

Assim, apresentamos aqui artigos que lançam um olhar, dentro do currículo formal, ora sobre o ensino médio regular, ora sobre a educação de jovens e adultos. E, fazendo um contraponto com o currículo formal, apresentamos ainda um artigo que trabalha com uma iniciativa formal de inovação curricular, a partir da introdução de oficinas nãoobrigatórias para os alunos da educação básica.

Quanto ao foco de pesquisa, apresentamos artigos que envolvem: o conhecimento de conteúdo dos alunos, o processo de aprendizagem dos mesmos, assim como investigações sobre estratégias pedagógicas docentes e suas escolhas a partir do universo de alunos atendidos. Esperamos, com essa seleção, instigar outros cursos de licenciatura a buscarem maior divulgação dos trabalhos de alunos da prática de ensino, mostrando como pesquisa e prática podem e devem dialogar na formação de nossos professores e ciências e biologia. 


\section{Agradecimentos}

Queremos agradecer aos alunos da Prática de Ensino de Ciências Biológicas da UFMG, Filipe Leão Morgan, Lia Cardoso Rocha e Thiago Cavanelas Gelape, por autorizarem a transcrição de seus depoimentos, enriquecendo portanto o conteúdo e a exposição de idéias nesse artigo.

\section{Referências Bibliográficas}

ANDRÉ, Marli. Avanços no Conhecimento Etnográfico da Escola. In: FAZENDA, Ivani C. (Org.). A Pesquisa em Educação e as Transformações do Conhecimento. 4.ed. Campinas: Papirus, 2002. p.99-110.

ANDRÉ, Marli. O Papel da Pesquisa na Articulação entre Saber e Prática Docente. In: CLAVES, S.M. \& TIBALLI, E.F. (Orgs.). Anais do VII ENDIPE, vol.II, Goiânia, 1994.

BROWN, A. L., COLLINS, A., \& DUIGUID, P. Situated cognition and the culture of learning. Educational Researcher, 18, p. 32-42. 1989.

CARVALHO, A. M. P. de. A influência das mudanças da legislação na Formação dos professores: as 300hs de estágio supervisionado. Ciência \& Educação 7(1), pp. 113$123,2001$.

DEMO, Pedro. Educar pela Pesquisa. SP: Autores Associados, 1996.

DEMO, Pedro. Pesquisa e Construção do Conhecimento. RJ: Tempo Brasileiro, 1994.

DEMO, Pedro. Pesquisa - princípio científico e educativo. SP: Cortez, 1991.

DRIVER, R. ASOKO, H., LEACH, J., MORTIMER, E. F., \& SCOTT, P.. Construindo conhecimento científico na sala de aula. Revista Química Nova na Escola, 1(9). p. 31-40, 1999.

FERREIRA, Marcia S., VILELA, Mariana L. \& SELLES, Sandra E. Formação Docente em Ciências Biológicas: estabelecendo relações entre a prática de ensino e o 
contexto escolar. In: SELLES, Sandra E. \& FERREIRA, Marcia S. (Orgs.). Formação Docente em Ciências: memórias e práticas. Niterói: Eduff, 2003. p.29-46.

FIEN, John. RAWLING, Richard. Reflective Practice: a case study of professional development for environmental education. The Journal of Environmental Education, Washington, DC, v.27, n.3, p.11-20, 1996.

GAUTHIER, C. et al. Por uma teoria da pedagogia: pesquisas contemporâneas sobre o saber docente. Ijuí: Ed. UNIJUÍ, 1998. 457p. (Coleção fronteiras da educação).

LAVE, J., \& WENGER, E. Situated learning: Legitimate peripheral participation. Cambridge: Cambridge University Press, 1991.

LUDKE, Menga. A Pesquisa na Formação do Professor. In: FAZENDA, Ivani C. (Org.). A Pesquisa em Educação e as Transformações do Conhecimento. 4.ed. Campinas: Papirus, 2002. p.111-120.

LUDKE, Menga. O Professor, seu Saber e sua Pesquisa. Educação e Sociedade, Campinas: CEDES, n.74, abr.2001.p.77-96.

MENDES, Regina. O Papel da Escola na Educação Ambiental: experiências e perspectivas de professores. Belo Horizonte: UFMG/FaE, 2002. (Dissertação, Mestrado em Educação).

MENEZES, Paulo. Tradição e Inovação no Ensino de Física: grupos colaborativos de professores dando estabilidade a mudanças. Belo Horizonte: UFMG/FaE, 2003. (Dissertação, Mestrado em Educação).

MIZUKAMI, Maria da Graça N. et al. Escola e Aprendizagem da Docência: processos de investigação e formação. São Carlos: EdUFSCar, 2002.

PEREIRA, Júlio Emílio D. Formação de Professores - pesquisa, representações e poder. Belo Horizonte: Autêntica, 2000.

PUTNAM, R. T., \& BORKO, H. (1997). Teacher Learning: Implications of new views of cognition. In: BIDDLE, B. J. (Ed.). International Handbook of Teachers and Teaching. Kluwer Academic Publishers, pp. 1223-1296, 1997.

SELLES, Sandra E. \& FERREIRA, Marcia S. (Orgs.). Formação Docente em Ciências: memórias e práticas. Niterói: Eduff, 2003. 176p. (Série Práxis Educativa; 1). 
SHULMAN, Lee S. Professing educational scholarship. In: Issues in Education Research: problems and possibilities. San Francisco: Jossey-Bass Publishers, 1999. p.159-165. apud LUDKE, Menga. O Professor, seu Saber e sua Pesquisa. Educação e Sociedade, Campinas: CEDES, n.74, abr.2001. p.77-96.

TARDIF, Maurice, LESSARD, Claude \& LAHAYE, Louise. Os professores face ao saber: esboço de uma problemática do saber docente. Teoria e Educação, Porto Alegre, n.4, p.215-233, 1991. 